\title{
Magnetita PaRA FiXAÇÃo de compostos tóxicos SOLUBILIZADOS DE RESÍDUOS DE FUNDIÇÃO DE CHUMBO
}

\section{USING MAGNETITE TO FIX TOXIC COMPOUNDS SOLUBILIZED FROM SOLID RESIDUES PRODUCED AT LEAD SMELTING PLANT}

\author{
EVELYN LOURES DE GODOI \\ Bióloga e aluna de Mestrado do CQMA/IPEN \\ Priscila Moreira Peres Garcia \\ Engenheira Química e aluna de Mestrado do CQMA/IPEN \\ NILCE ORTIZ \\ Pesquisadora Associada do CQMA/IPEN - Doutora em Tecnologia Nuclear - Aplicações \\ Código ABES: 024/06 Recebido: 21/02/06 Aceito: 18/07/07
}

\begin{abstract}
RESUMO
Um resíduo siderúrgico composto basicamente por magnetita $\left(\mathrm{Fe}_{3} \mathrm{O}_{4}\right)$ foi estudado como material adsorvente para fixação de íons metálicos presentes nos produtos lixiviados e solubilizados de secundários da unidade desativada de fundição de chumbo - Panelas, localizada na Bacia do Rio Ribeira de Iguape. Os leitos adsortivos preparados com a mistura Magnetita, Bentonita e Cinzas - MBC apresentaram 71,4\% de remoção de íons de chumbo e $26,9 \%$ de remoção de íons de zinco adicionados em concentrações semelhantes às medidas nos produtos lixiviados e solubilizados do secundário de fundição. Os valores de velocidade de adsorção obtidos foram proporcionais aos citados para adsorventes não convencionais em literatura e as equações propostas no modelo empírico apresentaram correspondência com os valores obtidos experimentalmente.
\end{abstract}

PALAVRAS-CHAVE: Magnetita, resíduos, siderurgia, adsorção e adsorvente

\section{INTRODUÇÃO}

No período de 1918 a 1995 foi realizada a extração de depósitos de chumbo e prata na bacia do Rio Ribeira de Iguape e durante este período de mineração não houve nenhum tipo de preocupação com o impacto ambiental da atividade mineradora. Os rejeitos, com diferentes teores de chumbo e zinco foram depositados diretamente sobre o solo. A utilização de barreiras geoquímicas que adsorvem e fixam os íons metálicos lixiviados e solubilizados de depósito de rejeitos de mineração, processamento e fundição ricos em chumbo e zinco evitaria o transporte destes contaminantes pelo meio hídrico e o aporte no sistema estuarino lagunar, promovendo a mitigação dos efeitos da presença destes metais tóxicos no sistema aquático (Cunha, 2003, Alloway e Ayres, 1994 e CETESB, 1986).

Um resíduo siderúrgico principalmente constituído por composto de ferro abundante e de baixo custo sendo utilizado como material adsorvente não convencional na confecção de barreiras geoquímicas tenderá a reduzir os custos de implantação e manutenção de processos de adsorção e de fixação de compostos tóxicos, que desta forma permanecem restritos a área contaminada, não atuando como fonte de contaminação dos meios hídricos, solos e sedimentos (Ortiz, 2000 e Ortiz et al, 2003).

A magnetita $\left(\mathrm{Fe}_{3} \mathrm{O}_{4}\right)$ empregada como material adsorvente não convencional na composição de barreiras geo- químicas apresenta ainda a vantagem de permitir o emprego de processos de separação magnética para a remoção do material adsorvente saturado. Os processos de adsorção e fixação dos íons metálicos na superfície da magnetita representam a concentração do metal na superfície e a possibilidade de remoção para a reutilização destes metais como matéria prima, num futuro próximo, quando as reservas minerais forem menos abundantes e o valor de venda do metal reprocessado compensar o custo do processo de recuperação.

O desenvolvimento de barreiras geoquímicas economicamente viáveis poderá auxiliar nos processos de fixação e remoção de compostos tóxicos solubilizados e lixiviados de depósitos em áreas abandonadas (ou sem responsável 
definido) de diversas atividades produtivas e potencialmente poluidoras como a química, a petroquímica e de mineração (Moeri et al, 2004).

As velocidades de adsorção são consideradas importantes na avaliação de um material adsorvente uma vez que seriam inaceitáveis valores de velocidade de adsorção muito abaixo do que é aceito e citado em literatura (Ortiz et al, 2003). A velocidade do processo de adsorção pode ser calculada considerando-se uma reação de primeira ordem. Os resultados experimentais são colocados no gráfico de $\log \left(\mathrm{C}_{\mathrm{e}}-\mathrm{C}\right)$ em função de $t$ e a equação da reta obtida pode ser usada no cálculo de $\mathrm{K}_{\mathrm{ad}}$ (Equação 1). Esse valor representa a quantidade de íons metálicos adsorvida por tempo de agitação (Namasivayam and Ranganathan, 1993).

$\log (\mathrm{Ce}-\mathrm{C})=\iota \frac{-\mathrm{Kad}}{2,303} m \mathrm{t}+\log \mathrm{qe}$

Sendo:

$\mathrm{C}_{\mathrm{e}}$ - Concentração do íon metal na condição de equilíbrio $\left(\mathrm{mg} \mathrm{L}^{-1}\right)$,

C - Concentração no tempo de agitação $\mathrm{t}$,

$\mathrm{k}_{\mathrm{ad}}$ - Velocidade de reação de adsorção $\left(\mathrm{mg} \mathrm{g}^{-1} \mathrm{~min}^{-1}\right)$,

$\mathrm{q}_{\mathrm{e}}-$ Quantidade de adsorbato por massa de material adsorvente $\left(\mathrm{mg} \mathrm{g}^{-1}\right)$,

$\mathrm{t}$ - tempo de agitação do processo de adsorção ( $\mathrm{min})$.

A constante de velocidade do siste$\mathrm{ma}\left(\mathrm{K}_{\mathrm{ad}}\right)$ poderá ser calculada a partir do coeficiente angular da equação de reta obtida e o $\log \mathrm{q}_{\mathrm{e}}$ a partir do coeficiente linear. Na Tabela 1 podem ser observados alguns valores de $\mathrm{K}_{\mathrm{ad}}$ citados em literatura para dois materiais adsorventes não convencionais (Lanouette, 1977 e Ortiz, 2000).

Os resultados experimentais de sistemas de adsorção para adsorventes não convencionais permitiram o desenvolvimento de um modelo empírico encontrado em literatura, Equação 2. O modelo matemático relaciona o tempo de agitação do sistema com a quantidade de adsorbato presente em solução e propõe a seguinte relação entre as espécies (Namasivayam et al, 1994; Namasivayam et al, 1995).

$\log \left(\mathrm{C}_{\mathrm{o}}-\mathrm{C}\right)=-\log \mathrm{K}^{\prime \prime}+$

$+\frac{1}{\mathrm{~A}} \log (\log (\mathrm{t}+1))$

Sendo:

C - Concentração inicial do íon metálico $\left(\mathrm{mg} \mathrm{L}^{-1}\right)$,

$\mathrm{C}$-Concentração no tempo de agitação $\mathrm{t}$ (minutos),

Tabela I - Valores de velocidades de adsorção $\left(K_{2 d}\right)$ para materiais adsorventes não convencionais (Ortiz, 2000)

\begin{tabular}{ccc}
\hline Material adsorvente & Adsorbato & $\begin{array}{c}\mathrm{K}_{\mathrm{ad}}\left(10^{-3}\right) \\
\left(\mathrm{mg}^{-1} \cdot \mathrm{min}^{-1}\right)\end{array}$ \\
\hline Lodo galvânico rico em Fe III e & $\mathrm{Pb} \mathrm{II}$ & 13 a 35 \\
Cr III & $\mathrm{Cd} \mathrm{II}$ & 7 a 25 \\
& $\mathrm{Ni} \mathrm{II}$ & 10 a 28 \\
Hidróxido de Fe III/Cr III & $\mathrm{Cr}$ VI & 75 a 87 \\
& paraquat & 5 a 18 \\
\hline
\end{tabular}

K” - Constante empírica do modelo cinético (adimensional),

A - Constante empírica do modelo cinético (adimensional),

Os valores de K" e A foram obtidos por meio das equações de reta a partir dos dados experimentais, no gráfico $\log (\log (t+1))$ em função de $\log \left(\mathrm{C}_{\mathrm{o}}-\mathrm{C}\right)$. Os valores do coeficiente angular e o linear foram utilizados para calcular as constantes K” e A. Onde o coeficiente angular corresponde a (1/A) e o coeficiente linear a $\left(-\log K^{\prime \prime}\right)$.

O presente trabalho descreve a execução do projeto de pesquisas que estuda a utilização de um resíduo siderúrgico principalmente constituído por magnetita como material adsorvente na composição de barreiras geoquímicas para a fixação dos íons metálicos tóxicos disponibilizados por processos de solubilização e lixiviação de um depósito de secundário de fundição de chumbo localizado em área próxima ao Rio Ribeira de Iguape, na divisa entre os Estados do Paraná e de São Paulo.

\section{METODOLOGIA}

$\mathrm{O}$ acesso à região da Bacia Hidrográfica do Rio Ribeira de Iguape é feito pela BR-116, que liga São Paulo a Curitiba, e boa parte de sua porção interna, contempla as drenagens de segunda, terceira e quarta ordem com acesso por estradas secundárias localizadas em diferentes municípios dos estados do Paraná e São Paulo. O depósito de secundários de fundição de chumbo de Panelas esta localizado próximo às antigas instalações de mineração no Vale do Ribeirão do Rocha entre as cidades de Cerro Azul e Adrianópolis no Estado do Paraná. Nesta área, o Rio Ribeira de Iguape marca a divisa entre o Estado do Paraná e o Estado de São Paulo de um lado com a cidade de Adrianópolis e do outro com a cidade Ribeira respectivamente (Cunha, 2003).
O resíduo siderúrgico principalmente constituído por magnetita foi obtido na etapa de purificação do ferro gusa para a obtenção do aço (Alper, 1995). As amostras coletadas apresentaram 26\% de umidade e foram caracterizadas utilizando as técnicas de difratometria de raios X, BET (medidas de área específica e volume de poros), análise granulométrica por sistema de peneiras, e a fração de menor diâmetro (<\#400 ASTM) foi analisada por sedimentação, utilizando-se o equipamento Cilas.

A concentração dos elementos químicos predominantes nas amostras de secundários de fundição de Panelas foram determinadas por fluorescência de raios X no aparelho Phillips - Modelo Magic Pro, e em seguida as amostras foram analisadas utilizando-se a técnica de difratometria de raios $\mathrm{X}$ no aparelho Bruker - AXS Modelo D8 Advance (projeto Multi-usuário Fapesp 96/09604-9).

As amostras dos secundários de fundição foram caracterizadas utilizando-se medidas de fluorescência de raios $\mathrm{X}$, difração de raios $\mathrm{x}$ (estrutura cristalina), análise granulométrica (distribuição granulométrica), ensaios de classificação de resíduos sólidos NBR 10.004 e na determinação dos produtos lixiviados e solubilizados (McKay et al,1980). Estudos do processo de lixiviação e de solubilização dos compostos metálicos presentes no secundário de fundição forneceram importantes indicações quanto a possibilidade de contaminação da área e da necessidade de processos de estabilização destes contaminantes impedindo que alcancem as águas de superfície (Ortiz, 2000).

A magnetita obtida na forma de resíduo siderúrgico não apresenta propriedades plásticas suficientes para a conformação em leitos adsorventes. Assim sendo foi necessária a colocação 
de aditivos na formulação da massa de conformação, as esferas obtidas foram preparadas a partir da adição de argila bentonita e cinzas de termoelétrica.

Cinzas de termoelétrica foram adicionadas à massa de conformação de esferas por apresentarem conteúdo energético para combustão interna, que após a queima a $600^{\circ} \mathrm{C}$ resulta em maior número de poros, aumento de área superficial e provável aumento na capacidade adsortiva. Amostras de cinzas de termoelétrica foram coletadas no sistema de ciclones da Usina Termoelétrica de Figueiras - Estado do Paraná, sendo principalmente constituída por carvão amorfo ( $40 \%$ em massa) e quando submetida a ensaios de Análise Térmica Diferencial (ATD) observouse que com o aquecimento o carvão presente na amostra sofre combustão e a partir da temperatura de $600^{\circ} \mathrm{C}$ podem ser observados apenas resíduos minerais.

Após a peletização as esferas $\mathrm{MBC}$ foram submetidas aos ensaios de determinação de resistência mecânica, sendo queimadas, submetidas à queda e à determinação de tensão de ruptura á compressão. Neste trabalho foi priorizado o estudo de leitos adsortivos constituídos por magnetita em sistemas de adsorção em leito móvel. Foram utilizados apenas os leitos adsorventes considerados estáveis após os ensaios de determinação de estabilidade química e mecânica. Os parâmetros de adsorção estudados foram: o tempo de agitação, a concentração inicial das soluções e o valor de pH (Ortiz et al, 2002 e McKay et al, 1980). Os adsorventes desenvolvidos foram utilizados para a adsorção e remoção dos íons metálicos chumbo e zinco em teores médios semelhantes aos observados nos produtos solubilizados e lixiviados das amostras de secundários de fundição de chumbo. As concentrações das soluções de chumbo e zinco foram determinadas por titulação complexometrica com solução de EDTA, amostras da solução inicial e da solução após 300 min de agitação foram também analisadas por espectroscopia de plasma induzido - ICP/AES.

Os ensaios em leito móvel foram realizados com agitação mecânica continua por $5 \mathrm{~h}$ utilizando-se $1 \mathrm{~g}$ de adsorvente, $500 \mathrm{~mL}$ de solução de nitrato de chumbo, $\mathrm{Pb}\left(\mathrm{NO}_{3}\right)_{2}$, ou nitrato de zinco $\mathrm{Zn}\left(\mathrm{NO}_{3}\right)_{2}$ e a coleta de alíquotas em diferentes tempos de agitação 30 , 120 e $300 \mathrm{~min}$, todas em duplicata.
Os ensaios de adsorção foram realizados em pH 5. Em ensaios realizados anteriormente observou-se que em sistemas mais ácidos, com valores de $\mathrm{pH}$ menor que 5 ocorre a interferência de processos de dissolução dos corpos conformados com aumento de concentração de ferro no sistema e interferência nas medidas complexométricas (Ortiz, 2000). As esferas MBC saturadas após os ensaios de adsorção de íons de chumbo foram embutidas em resina e sofreram corte transversal resultando em duas metades que foram analisadas utilizando-se a técnica de microscopia eletrônica de varredura (MEV). O aparelho utilizado foi o Philips Mod. XL-30 do Laboratório de Microscopia Eletrônica do Centro de Ciência e Tecnologia do Materiais - CCTM/IPEN e foram obtidas fotos com aumento de 250x com analise de proporção entre chumbo adsorvido e ferro presente na esfera de magnetita em pontos com diferentes distâncias da superfície (Padilha e Ambrosio, 1985).

\section{RESULTADOS E DISCUSSÃO}

Um resíduo siderúrgico obtido na etapa de produção do aço (17 ton/dia) foi caracterizado e observou-se ser constituído principalmente por magnetita $\left(\mathrm{Fe}_{3} \mathrm{O}_{4}\right)$ em partículas de diâmetro pequeno $(\phi<0,15 \mathrm{~mm})$ e as quantidades de impurezas ao principal constituinte são muito pequenas não interferindo com os valores de concentração dos íons de chumbo e de zinco medidos.

Os valores de concentração de cálcio e de magnésio observados na análise química das amostras de secundários de fundição de chumbo indicam a presença de carbonato de cálcio e magnésio (Tabela 2). Esta composição era esperada, uma vez que a calcita e a dolomita são predominantes na região. A análise química obtida apresentou concentração de $\mathrm{PbO}$ de $0,75 \%$ e de $1,05 \%$ para $\mathrm{ZnO}$. Estes teores representam compostos de elevada toxicidade, com baixos limites permissíveis para descarte pela legislação ambiental, em matriz de carbonatos com alta solubilidade em meio ácido. Os valores de concentração de ferro obtidos para a amostra de secundários de fundição podem ser considerados uma indicação da presença de sulfeto de ferro amorfo como principal constituinte (em aproximadamente 10\%). Este composto quando sujeito a umidade e calor pode criar ambiente favorável à formação de ácido sulfúrico, que estando presente no depósito aumentará a disponibilidade dos íons zinco e chumbo, que desta forma podem ser lixiviados e solubilizados para o meio hídrico.

Os ensaios de caracterização e de classificação de resíduos foram realizados para os secundários de fundição, considerados mais representativos do depósito de rejeitos de chumbo abandonados. As amostras dos secundários de fundição foram submetidas aos ensaios para classificação de resíduos NBR 10.004. Os resultados obtidos nos testes de solubilização são apresentados na Tabela 3 e os resultados obtidos nos testes de lixiviação na Tabela 4 (ABNT, 2004).

Os resultados das Tabelas 3 e 4 são concordantes com os obtidos anteriormente na análise química, onde alem dos elementos característicos de solos como o silício, alumínio e

Tabela 2 - Análise química de secundários de fundição - Panelas

\begin{tabular}{cc}
\hline Elementos químicos & Secundários de fundição (\%) \\
\hline $\mathbf{F e}_{2} \mathbf{O}_{3}$ & $\mathbf{1 0 , 2}$ \\
$\mathrm{CaO}$ & 8,44 \\
$\mathrm{SiO}_{2}$ & 27,5 \\
$\mathbf{Z n O}$ & $\mathbf{1 , 0 5}$ \\
$\mathrm{MgO}$ & 4,35 \\
$\mathrm{Al}_{2} \mathrm{O}_{3}$ & 5,99 \\
$\mathbf{P b O}$ & $\mathbf{0 , 7 5}$ \\
$\mathrm{BaO}$ & 24,9 \\
$\mathrm{SO}_{3}$ & 13,9 \\
$\mathrm{Outros}$ & 2,92 \\
\hline
\end{tabular}


ferro(elementos predominantes nos secundário de fundição de chumbo), observa-se a presença de íons de cálcio e de magnésio em proporçôes características de matrizes de carbonatos. Este fato evidencia a possibilidade de, em meio ácido, ocorrer solubilização e carreamento de íons de cálcio, magnésio e também de compostos de maior toxidez presentes na matriz de carbonatos, como os compostos de chumbo e de zinco, que desta forma tornam-se mais disponíveis para a contaminação de águas de superfície.

Os resultados obtidos na análise química dos produtos de solubilização e de lixiviação indicam que o resíduo é perigoso, classe I, com teores de chumbo acima dos limites permitidos pela legislação (ABNT, 2004).

As esferas utilizadas neste estudo foram as que apresentaram maior estabilidade nos ensaios de estabilidade química e mecânica, as esferas MBC. $\mathrm{Na}$ Tabela 5 podem ser observados os valores de porcentagem de remoção de chumbo e de zinco, a capacidade adsortiva $\left(q_{e}\right)$ e a concentração de equilíbrio $\left(\mathrm{C}_{\mathrm{e}}\right)$.

Os resultados obtidos para as esferas MBC na adsorção de chumbo e zinco indicam maior eficiência da remoção de íons de chumbo em relação aos de zinco. Este comportamento era esperado uma vez que o processo de adsorção de zinco tende a apresentar menor energia de ligação que os íons de chumbo, comparação com o raio iônico de $1,1610^{-9} \mathrm{~m}$ para o íon de chumbo e de $0,8310^{-9} \mathrm{~m}$ para o íon do zinco. Estudos anteriores já apresentaram este aspecto na comparação da porcentagem de adsorção e remoção com o tamanho do íon hidratado da espécie adsorvida (Ortiz, 2000).

A velocidade do processo de adsorção pode ser calculada considerando-se como reação de adsorção de primeira ordem. Os resultados experimentais são colocados no gráfico de $\log \left(\mathrm{C}_{\mathrm{e}} \mathrm{C}\right)$, no eixo y, e o tempo de agitação do sistema de adsorção ( $\mathrm{min})$, no eixo x. A equação da reta obtida foi usada no cálculo de $\mathrm{K}_{\mathrm{ad}}$. Esse valor representa a quantidade de metal adsorvida por um material adsorvente em um intervalo de tempo de agitação.

Os estudos cinéticos de adsorção dos íons chumbo e zinco pelas esferas MBC foram executados variando-se as concentrações iniciais. Os resultados obtidos permitiram a confecção da Fi-
Tabela 3 - Concentração dos elementos químicos preponderantes no produto solubilizado da amostra de secundário de fundição - Panelas

\begin{tabular}{cccc}
\hline $\begin{array}{c}\text { Elementos } \\
\text { analisados }\end{array}$ & $\begin{array}{c}\text { Limite máximo } \\
\text { permitido } \\
\text { NBR } 10.004 \\
\left(\mathrm{mg} \mathrm{L}^{-1}\right)\end{array}$ & $\begin{array}{c}\text { Resultados } \\
\text { obtidos }\left(\mathrm{mg} \mathrm{L}^{-1}\right)\end{array}$ & $\begin{array}{c}\text { Técnicas analíticas } \\
\text { utilizadas }\end{array}$ \\
\hline Alumínio & 0,2 & $<0,20$ & AAS \\
Arsênio & 0,05 & $<0,02$ & AAS \\
Chumbo & $\mathbf{0 , 0 5}$ & $\mathbf{0 , 0 3}$ & AAS \\
Cálcio & - & 234 & AAS \\
Ferro & 0,30 & $<0,15$ & AAS \\
Enxofre total & - & $<10$ & Turbidimetria \\
Magnésio & - & 10,90 & AAS \\
Silício & - & 2,11 & AAS \\
Zinco & $\mathbf{5 , 0}$ & $\mathbf{5 , 6 3}$ & AAS \\
\hline
\end{tabular}

AAS: Espectrometria de Absorção Atômica

Tabela 4 - Concentração dos elementos químicos preponderantes no produto lixiviado da amostra de secundário de fundição - Panelas

\begin{tabular}{cccc}
\hline $\begin{array}{c}\text { Elementos } \\
\text { analisados }\end{array}$ & $\begin{array}{c}\text { Limite máximo } \\
\text { permitido } \\
\text { NBR } 10.004 \\
\left(\mathrm{mg} \mathrm{L}^{-1}\right)\end{array}$ & $\begin{array}{c}\text { Resultados } \\
\text { obtidos }\left(\mathrm{mg} \mathrm{L}^{-1}\right)\end{array}$ & $\begin{array}{c}\text { Técnicas analíticas } \\
\text { utilizadas }\end{array}$ \\
\hline Alumínio & - & 9,50 & AAS \\
Arsênio & 5,0 & $<0,10$ & AAS \\
Chumbo & $\mathbf{5 , 0}$ & $\mathbf{3 9 , 0}$ & AAS \\
Cálcio & - & 305 & AAS \\
Ferro & - & 0,49 & AAS \\
Enxofre total & - & $<10$ & Turbidimetria \\
Magnésio & - & 17,80 & AAS \\
Silício & - & 4,90 & AAS \\
Zinco & - & $\mathbf{6 1 , 0}$ & AAS \\
\hline
\end{tabular}

AAS: Espectrometria de Absorção Atômica

Tabela 5 - Resultados dos ensaios de adsorção de chumbo e zinco utilizando-se esferas das misturas magnetita-bentonita-cinzas (MBC)

\begin{tabular}{cccc}
\hline $\begin{array}{c}\text { Ín Metálico } \\
\text { adsorvido }\end{array}$ & $\begin{array}{c}\text { Remoção de } \\
\text { Chumbo } \\
(\%)\end{array}$ & $\begin{array}{c}\mathrm{q}_{\mathrm{e}} \text { Médio } \\
\left(\mathrm{mg} \cdot \mathrm{g}^{-1}\right)\end{array}$ & $\begin{array}{c}\mathrm{C}_{\mathrm{e}} \text { Médio } \\
\left(\mathrm{mg} . \mathrm{L}^{-1}\right)\end{array}$ \\
\hline Chumbo & 71,4 & 28,3 & 28,4 \\
Zinco & 26,9 & 14,4 & 57,5 \\
\hline
\end{tabular}


gura 1, onde se determinou a velocidade de adsorção de íons de chumbo em solução no intervalo de concentração inicial de $14 \mathrm{mg} \cdot \mathrm{L}^{-1}$ a $58 \mathrm{mg} \cdot \mathrm{L}^{-1}$.

As curvas representadas na Figura 1 e 2 apresentam aspecto linear de velocidade demonstrando que soluções mais concentradas apresentam declividade negativa maior que as menos concentradas. Na Tabela 6 podem ser observados os valores da constante de velocidade de adsorção $\left(\mathrm{K}_{\mathrm{ad}}\right)$ calculados a partir das equaçôes de reta obtidas.

Analisando-se a Tabela 6 observa-se pequena variação nos valores de constante de velocidade obtidos de 4,6 a $18,410^{-3} \mathrm{mg} \cdot g \cdot \mathrm{min}^{-1}$ e que os valores de $\mathrm{K}_{\mathrm{ad}}$ obtidos estão na mesma faixa de valores de velocidade de adsorção encontrados para outros adsorventes não convencionais em literatura (Tabela 1) com a presença de alguns valores discordantes, para o chumbo $K_{a d}=4,6 \cdot 10^{-3} \mathrm{mg} \cdot \mathrm{g}^{-1} \cdot \mathrm{min}^{-1}$ para $\mathrm{C}_{\mathrm{i}}^{\mathrm{ad}}=34,16 \mathrm{mg} \mathrm{L}^{-1}$ e para o zinco de 9,2 $\cdot 10^{-3} \mathrm{mg} \cdot \mathrm{g}^{-1} \cdot \mathrm{min}^{-1}$ para $\mathrm{C}_{\mathrm{i}}=79,78 \mathrm{mg} \mathrm{L}^{-1}$. Apesar dos pontos discordantes observa-se tendência ao aumento da velocidade de adsorção com o aumento da concentração inicial. Este efeito pode ser explicado ao considerar-se que, em suspensóes mais concentradas há maior número de íons disponíveis para choques com os sí- tios ativos presentes na superfície do sólido adsorvente resultando em maior desenvolvimento do processo de adsorção.

A Equação 2 de modelo cinético de adsorção, obtida em literatura, foi utilizada para o cálculo da concentração dos íons metálicos chumbo e zinco em diferentes intervalos de tempo de agitação. As constantes adimensionais A e K" foram obtidas empiricamente por meio da construção das retas $\log (\log (\mathrm{t}+1))$ no eixo das abscissas e $\log (\mathrm{C}-\mathrm{Co})$ no eixo das ordenadas em processos de adsorção com diferentes concentrações iniciais, Figuras 3 e 4 .

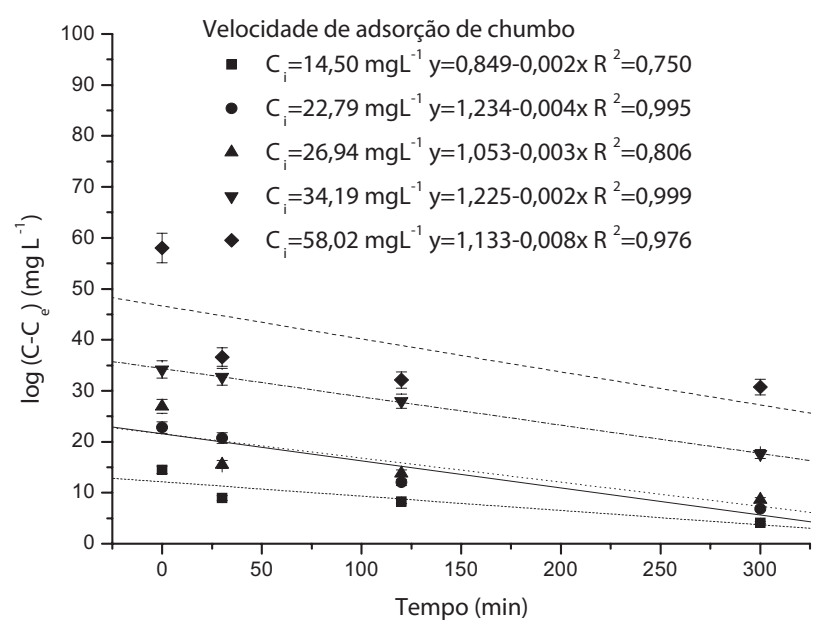

Figura I - Variação da concentração de chumbo em diferentes intervalos de tempo de agitação, determinação da equação do modelo cinético de variação da concentração por tempo

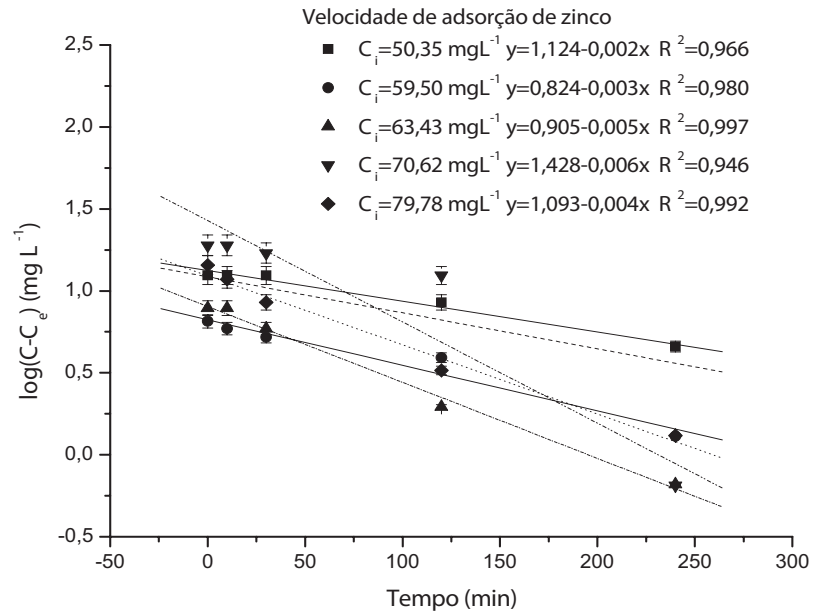

Figura 2 - Concentração de zinco por tempo de agitação. Determinação das equações de retas para cálculo de velocidade de adsorção para esferas MBC

Tabela 6 - Velocidade de adsorção $\left(K_{a d}\right)$ calculada a partir do coeficiente angular das equações de reta obtidas nas Figuras I e 2 com diferentes valores de concentração inicial

\begin{tabular}{ccc}
\hline Íon metálico adsorvido & $\begin{array}{c}\text { Concentração inicial } \\
( \pm 0,02) \mathrm{mg} \cdot \mathrm{L}^{-1}\end{array}$ & $\begin{array}{c}\mathrm{K}_{\mathrm{ad}} 10^{-3}( \pm 0,2) \\
\left(\mathrm{mg}^{-1} \cdot \mathrm{min}^{-1}\right)\end{array}$ \\
\hline Chumbo & 14,50 & 4,6 \\
22,79 & 9,2 \\
26,94 & 6,9 \\
34,16 & 4,6 \\
& 58,02 & 18,4 \\
\multirow{2}{*}{ Zinco } & 50,35 & 4,6 \\
& 59,50 & 6,9 \\
& 63,43 & 11,5 \\
& 70,62 & 13,8 \\
& 79,78 & 9,2 \\
\hline
\end{tabular}




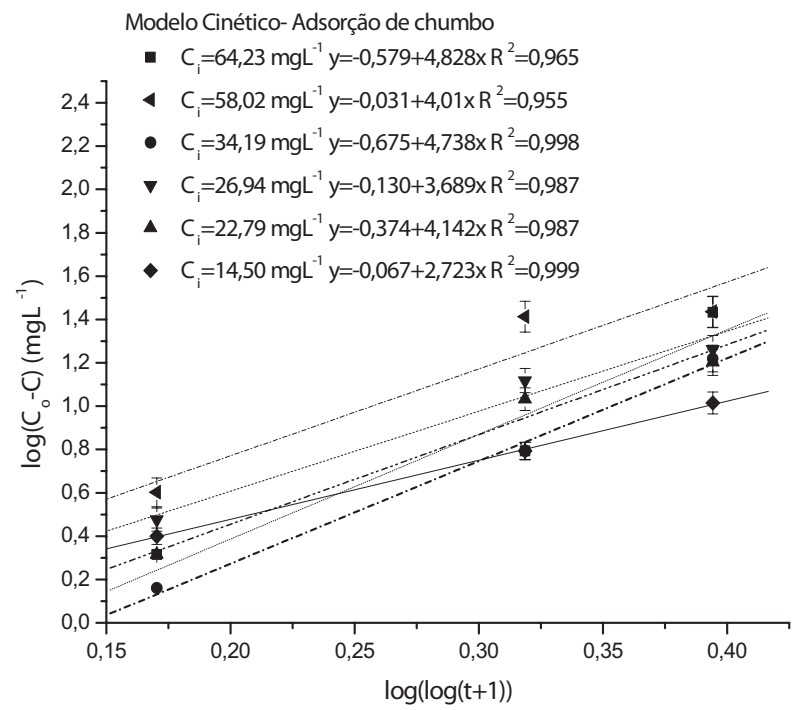

Figura 3 - Concentração de chumbo em diferentes intervalos de tempo de agitação, determinação da equação do modelo empírico de variação da concentração em função do tempo

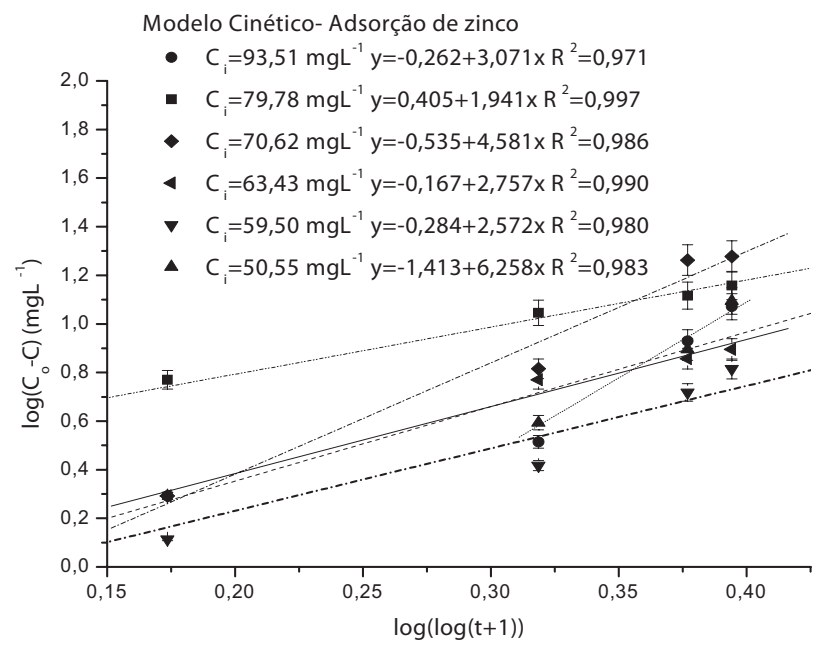

Figura 4 - Concentração de zinco em diferentes intervalos de tempo de agitação, determinação da equação do modelo empírico de variação da concentração em função do tempo
Os valores de K" e de A foram calculados a partir dos coeficientes angulares e lineares das equaçóes de retas obtidas nas Figuras 3 e 4. Após a determinação de $\mathrm{K}$ ” e de $\mathrm{A}$ os valores foram utilizados na Equação 2 para a obtenção das Equações 3 e 4. Estas equaçōes permitiram o calculo das concentraçôes dos íons de chumbo e de zinco $(\mathrm{C})$ nos diferentes intervalos de agitação $(t)$. Os valores obtidos nos cálculos realizados foram comparados com os valores medidos experimentalmente, Tabela 7.

Analisando-se os resultados de concentração obtidos por meio da equação do modelo cinético empírico com aqueles obtidos experimentalmente pode-se observar que apresentam variação menor que $10 \%$. Uma indicação que a Equação 2 pode ser utilizada para a determinação de $\mathrm{C}$ em diferentes valores de $\mathrm{t}$ em sistemas adsortivos com condições semelhantes de estudo.

Para adsorção de íosn de chumbo:

$\log (\log (\mathrm{t}+1))=\log 1,49+$

$+0,367 \log \left(\mathrm{C}_{\mathrm{o}}-\mathrm{C}\right)$

Para adsorção de íons de zinco:

$\log (\log (\mathrm{t}+1))=\log 1+$

$+0,398 \log \left(\mathrm{C}_{\mathrm{o}}-\mathrm{C}\right)$
As imagens obtidas por microscopia eletrônica de varredura permitiram a observação de corte transversal da esfera saturada comprovando a presença de uma camada superficial com um composto de morfologia acicular mais clara, diferente dos grãos constituintes da esfera. Esta diferença na estrutura sugere a formação de um composto na superfície com peso atômico maior do que o observado para a magnetita, principal constituinte da esfera (Figura 5).

Durante a observação com aumento de 250x selecionou-se 6 pontos no corte transversal pertencentes a uma reta da superfície em direção ao centro da esfera, em cada ponto foi feita a análise porcentual de elementos químicos preponderantes por Espectroscopia de Energia Dispersiva (EDX). Os resultados podem ser observados na Tabela 8 .

Os resultados obtidos indicam que as esferas saturadas apresentam os íons de chumbo adsorvidos na superfície em até $10 \mu \mathrm{m}$ de profundidade. Esta observação sugere que o processo é predominantemente adsortivo e que há possibilidade de remoção dos íons adsorvidos por meio de moagem leve com desbaste até $10 \mu \mathrm{m}$ de profundidade. Este processo dará origem a uma nova superfície na esfera com 5,08\% de chumbo que poderá ser utilizada novamente nos ensaios de adsorção, a possibilidade de remoção do metal adsorvido por desbaste da superfície seguido da separação das esferas pelas propriedades magnéticas e reutilização das esferas em um novo processo de adsorção.

\section{CONCLUSÕES}

O resíduo siderúrgico principalmente constituído por magnetita finamente dividida apresenta condições favoráveis a sua utilização como material adsorvente em processos de adsorção e fixação de compostos tóxicos solúveis. Os leitos de adsorção podem ser preparados em esferas de magnetita a partir da mistura magnetita-bentonita-cinzas. Os secundários de fundição de chumbo são principalmente constituídos por calcita e dolomita com compostos de chumbo e de zinco, que embora ocorram em pequena quantidade apresentam elevada toxidez em uma matriz de alta solubilidade. Os valores de velocidade de adsorção obtidos foram proporcionais aos citados para adsorventes não convencionais em literatura e as equações propostas no modelo empírico apresentaram correspondência com os valores obtidos experimentalmente. $\mathrm{O}$ material adsorvente conformado em esferas $\mathrm{MBC}$ em leito 
Tabela 7 - Concentração resultante do cálculo do modelo empírico e os valores obtidos experimentalmente em sistema com concentração inicial de chumbo $C_{0}=34,19 \mathrm{mg} \mathrm{L}^{-1}$ e concentração inicial de zinco $\mathrm{C}_{0}=59,50 \mathrm{mg} \mathrm{L}^{-1}$

\begin{tabular}{cccc}
\hline Tempo & $\mathrm{C}_{\text {exp. }} \mathrm{Pb}$ & $\mathrm{C}_{\text {calc. }} \mathrm{Pb}$ & \% da diferença \\
\hline 30 & 32,74 & 29,77 & 9,1 \\
120 & 25,97 & 23,22 & 10 \\
300 & 17,61 & 16,59 & 5,6 \\
Tempo & $\mathrm{C}_{\text {exp. }} \mathrm{Zn}$ & $\mathrm{C}_{\text {calc }} . \mathrm{Zn}$ & \% da diferença \\
\hline 10 & 58,35 & 58,40 & 0,1 \\
30 & 58,20 & 55,48 & 4,7 \\
120 & 56,89 & 53,22 & 6,5 \\
240 & 54,27 & 50,70 & 6,6 \\
300 & 52,97 & 49,78 & 6,0 \\
\hline
\end{tabular}

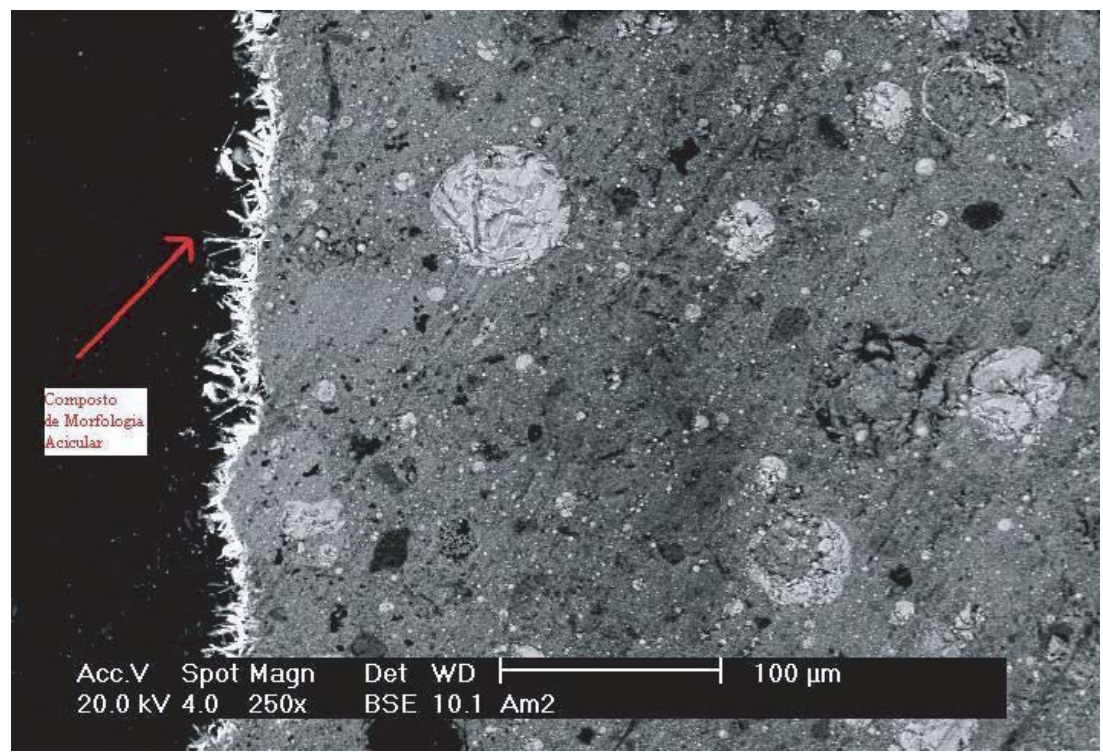

Figura 5 - Micrografia da superfície do corte transversal de esfera MBC saturada com íons de chumbo, aumento de 250x

Tabela 8 - Valores de concentração porcentual dos elementos preponderantes da esfera saturada com chumbo em diferentes distâncias da superfície

\begin{tabular}{cccc}
\hline Ponto & $\begin{array}{c}\text { Distancia da } \\
\text { superfície }(\mu \mathrm{m})\end{array}$ & Chumbo (\%) & Ferro (\%) \\
\hline 1 & 0 & 88,8 & 0,6 \\
2 & 10 & 5,08 & 81,5 \\
3 & 20 & 4,74 & 82,6 \\
4 & 30 & 2,75 & 88,0 \\
5 & 40 & 3,29 & 90,8 \\
6 & 50 & 2,08 & 92,6 \\
7 & 60 & 1,64 & 92,3 \\
\hline
\end{tabular}

móvel apresenta remoção de $71,4 \%$ de íons de chumbo e de $26,9 \%$ de zinco em soluçôes com teores semelhantes aos medidos nos produtos solubilizados e lixiviados de amostras dos secundários de fundição de chumbo. Os compostos de chumbo presentes na superfície são observados até $10 \mu \mathrm{m}$ de profundidade o que confirma o processo de adsorção e sugere que as esferas MBC saturadas podem ser desbastadas, separadas do composto de chumbo por separação magnética e reutilizadas em novo processo adsortivo.

\section{AGRADECIMENTOS}

Agradecemos ao Dr Joel Barbujiani Sígolo do Instituto de Geociências da USP pelo auxílio no desenvolvimento dos trabalhos em campo, a Fundação de Amparo a Pesquisa do Estado de São Paulo - FAPESP e ao Conselho Nacional de Pesquisa e Desenvolvimento - CNPq.

\section{REFERÊNCIAS}

ALLOWAY, B.J; AYRES, D.C. Organic pollutants. In: CHEMICAL PRINCIPLES OF ENVIRONMENTAL POLLUTION - Blackie Academic \& Professional, 2nd Ed, 196-259 p. 1994.

ALPER, A.M., Steel Manufacturer. In: ENCICLOPEDIA OF SCIENCE AND TECHNOLOGY, n. 13, p. 89-102. 1960.

ASSOCIAÇÃO BRASILEIRA DE NORMAS TÉCNICAS. Resíduos sólidos-Classificação. Rio de Janeiro: ABNT, (NBR 10.004). 2004.

COMPANHIA DE TECNOLOGIA DE SANEAMENTO BÁSICO-CETESB. Avaliação dos niveis de contaminação por metais pesados $e$ pesticidas organoclorados na água, ictiofauna e outros organismos aquáticos do complexo estuarino - lagunar de Iguape-Cananéia. Relatório Final, 68p. São Paulo, 1986.

CUNHA, F.G. - Estudos de geoquímica ambiental no Vale do Ribeira, nos Estados de São Paulo e Paraná e o impacto na saúde pública. IG - Universidade Estadual de Campinas - UNICAMP, 111p. 2003.

LANOUETTE, K.H. Heavy metals removal. In: CHEMICAL ENGINEERING DESKBOOK ISSUE 17, p. 73-80. 1977.

MCKAY,G.; OTTERBURN, M.S.; SWEENEY, A.G. The removal of color from effluent using various adsorbents - III Silica. Rate Process, Water Research, n.14, p. 21-25, 1980.

MOERI, E; COELHO, R.; MARKER, A. Remediação e Revitalização de Areas Contaminadas. 2a.Ed, São Paulo, Signus, 233 p. 2004.

NAMASIVAYAM, C.; RANGANATHAN, K. Waste $\mathrm{Fe}(I I I) / C r(I I I)$ hydroxide as adsorbent for the removal of $C r$ VI from aqueous solution on chromium plating industry wastewater. Environmental Pollution, n.82, p. 255-261, 1993. 
NAMASIVAYAM, C.; RANGANATHAN, K. Removal of $\mathrm{Pb}(\mathrm{II}), \mathrm{Cd}(\mathrm{II}), \mathrm{Ni}(\mathrm{II})$ and mixture of metal ions by adsorption onto waste $\mathrm{Fe}(I I I) / \mathrm{Cr}$ (III) hydroxide and fixed bed studies. Environmental Technology, n. 16, p. 851-860, 1995.

NAMASIVAYAM, C.; THAMARAISELVI, K.; YAMUNA, R.T. Removal of paraquat by adsorption on waste $\mathrm{Fe}(I I I) / \mathrm{Cr}(I I I)$ hydroxide. Adsorption Rates and Equilibrium Studies Pesticide Science, n. 41, p. 7-12, 1994.

ORTIZ, N.; PIRES, M.A.F.; BRESSIANI, J.C Use of steel converter slag as nickel adsorber to wastewater treatment. Waste Management Journal, n. 21, p. 631-635, 2001.

ORTIZ, N. Estudo da utilização de magnetita como material adsorvente nos metais $\mathrm{Cu}^{2+}, \mathrm{Pb}^{2+}$ $\mathrm{Ni}^{2+} e \mathrm{Cd}^{2+}$ em solução. Tese Doutorado - Instituto de Pesquisas Energéticas e Nucleares - IPEN, 158p. São Paulo, 2000.

ORTIZ, N. et al. Estudo da estabilidade química da magnetita utilizada como adsorvedor na remoção de compostos orgâninicos de soluçōes. Cerâmica n. 49 , p. 216-222, 2003

PADILHA, A.F;; AMBRÓSIO Fº, F. Técnicas de análise microestrutural. $1^{a} \mathrm{Ed}$, São Paulo Hemus, 190p. 1985.

RAMAKRISHINA, K.R.; VIRARAGHVAN, T. Use of slag for dye removal. Waste Management, n. 17, p. 483-488, 1997.

Endereço para correspondência:

Nilce Ortiz

Centro de Química e Meio

Ambiente - CQMA

Instituto de Pesquisas Energéticas

e Nucleares - IPEN

Av. Prof. Lineu Prestes, 2242

Cidade Universitária - Butantã /USP

05508-000 São Paulo - SP - Brasil

nortiz@ipen.br 